\title{
Effect of hydrogenative regeneration on the activity of beta and Pt-Beta zeolites during the transalkylation of toluene with 1,2,4-trimethylbenzene
}

DOI:

10.1016/j.micromeso.2019.109737

\section{Document Version}

Accepted author manuscript

Link to publication record in Manchester Research Explorer

Citation for published version (APA):

Almulla, F. M., Zholobenko, V. I., Tedstone, A. A., Jumah, A. B., Aldossary, M. R., \& Garforth, A. A. (2019). Effect of hydrogenative regeneration on the activity of beta and Pt-Beta zeolites during the transalkylation of toluene with 1,2,4-trimethylbenzene. Microporous and Mesoporous Materials, 293, [109737].

https://doi.org/10.1016/j.micromeso.2019.109737

\section{Published in:}

Microporous and Mesoporous Materials

\section{Citing this paper}

Please note that where the full-text provided on Manchester Research Explorer is the Author Accepted Manuscript or Proof version this may differ from the final Published version. If citing, it is advised that you check and use the publisher's definitive version.

\section{General rights}

Copyright and moral rights for the publications made accessible in the Research Explorer are retained by the authors and/or other copyright owners and it is a condition of accessing publications that users recognise and abide by the legal requirements associated with these rights.

\section{Takedown policy}

If you believe that this document breaches copyright please refer to the University of Manchester's Takedown Procedures [http://man.ac.uk/04Y6Bo] or contact uml.scholarlycommunications@manchester.ac.uk providing relevant details, so we can investigate your claim.

\section{OPEN ACCESS}


Microporous \& Mesoporous Materials

Elsevier Editorial System(tm) for

Manuscript Draft

Manuscript Number: MICMAT-D-19-01405R2

Title: Effect of hydrogenative regeneration on the activity of Beta and Pt-Beta zeolites during the transalkylation of toluene with 1,2,4trimethylbenzene

Article Type: Full length article

Keywords: transalkylation, toluene, 1,2,4-trimethylbenzene, xylene, Beta, deactivation, regeneration, time-on-stream

Corresponding Author: Dr. Faisal M Almulla,

Corresponding Author's Institution: Saudi Aramco

First Author: Faisal M Almulla

Order of Authors: Faisal M Almulla; Vladimir I Zholobenko; Aleksander A Tedstone; Abdulrahman Z Bin Jumah; Mohammed R Aldossary; Arthur A Garforth

Abstract: Catalyst deactivation remains a main challenge in the transalkylation process. To develop a cost-effective catalyst, improving the regeneration characteristics of Beta and Pt-Beta catalysts was investigated. Both Beta and Pt-Beta catalysts were studied in transalkylation in the presence of hydrogen. The regeneration process was carried out using hydrogen for four cycles of operation (30 hours on stream per cycle). A Pt-Beta catalyst with enhanced regeneration and activity characteristic relative to the parent materials is presented, and found to be stable, with the activity fully restored by regeneration with hydrogen at 500 oC. The activity of the parent Beta dropped gradually after each cycle suggesting that the hydrogen alone at 500 oC was insufficient in removing the coke formed during the reaction. The drop in activity was attributed to the disappearance of Brønsted acid sites over the spent Beta catalyst due to the growth of coke molecules trapped in the zeolite micropores leading to the formation of highly polyaromatic molecules blocking those active sites. This limitation can be effectively overcome by platinum addition which enhanced the removal of coke during the regeneration via hydrocracking. 


\section{A point-by-point response to reviewers:}

We thank the reviewer for his comments and respond as follows:

Reviewer 2:

Figure 5" Answer: IR spectra of fresh, spent and regenerated Pt/Beta is added to Figure 5." The adjustment to Figure 5 is not shown in the figure included in this manuscript to be reviewed.

Answer: The adjustment was added to Figure 6 (this is because of the addition of Figure 5 in the revised manuscript). This correction was reflected into the manuscript. 


\section{Highlights}

- Deactivation of Beta is mainly due to the disappearance of Brønsted acid sites.

- Regeneration of Beta using $\mathrm{H}_{2}$ alone, at $500{ }^{\circ} \mathrm{C}$, was insufficient in removing coke precursors.

- Addition of very low Pt levels (0.08 wt. \%) enhanced not only the activity of Beta but also, the restoration of activity after multiple of cycles ( $30 \mathrm{~h}$ per cycle). 


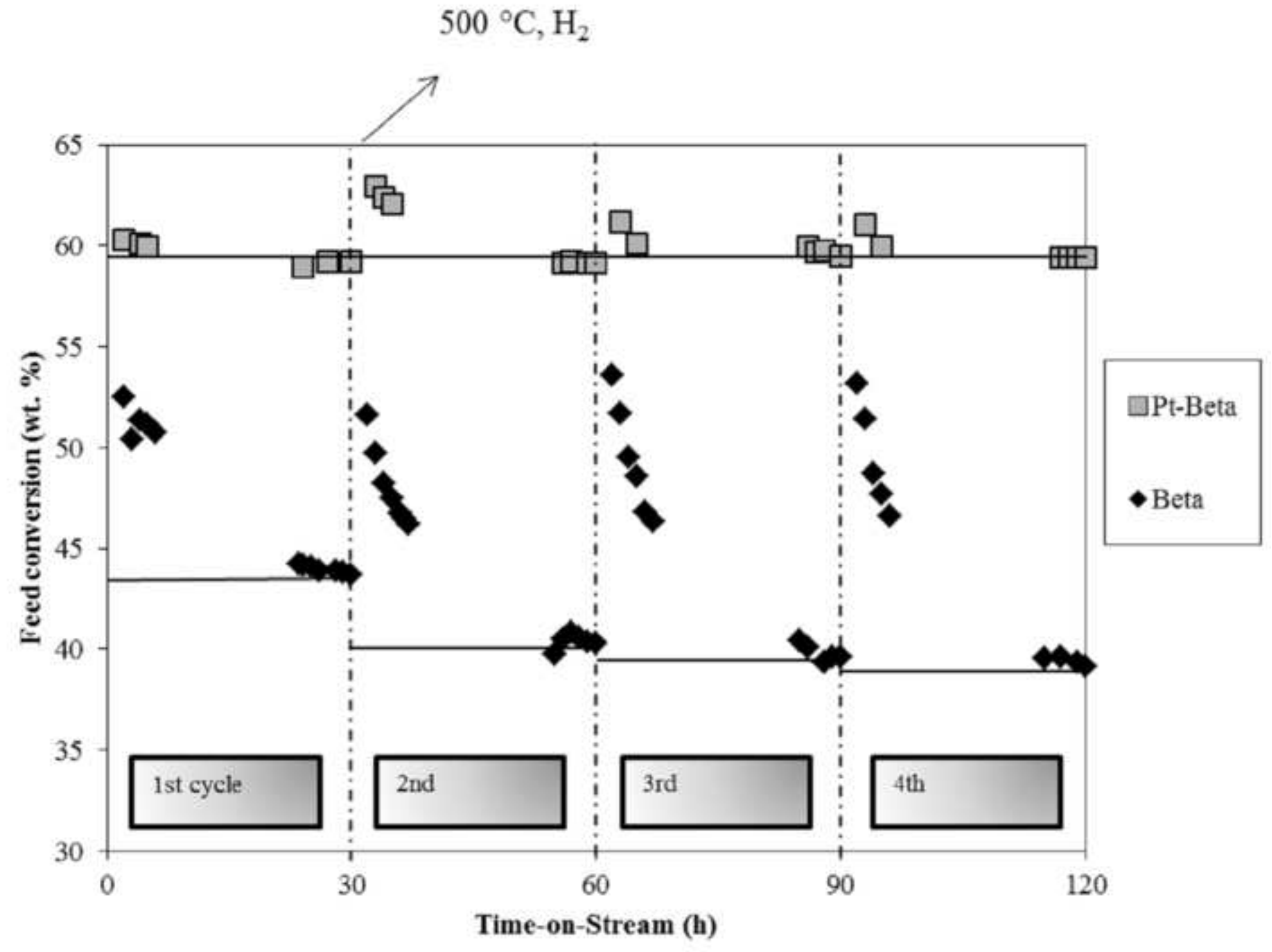




\section{Contents}

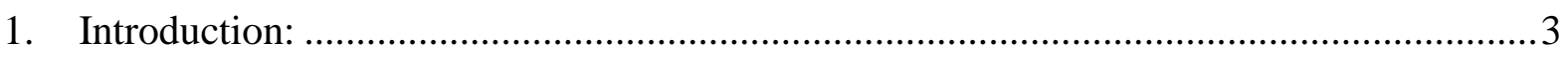

2. Experimental procedure .............................................................................

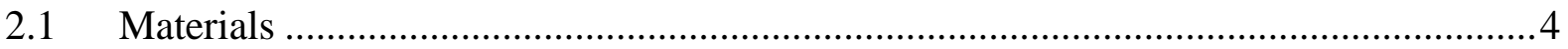

2.2 Catalyst preparation ........................................................................................

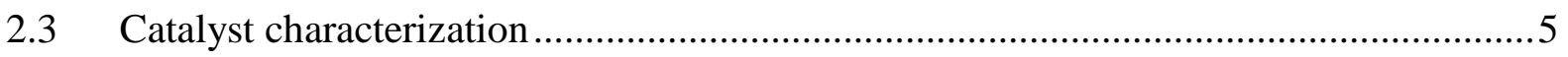

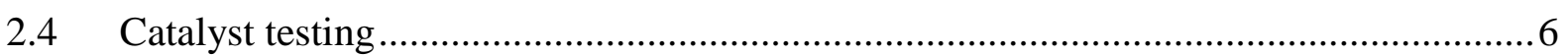

$2.5 \quad$ Feed and product analysis ..........................................................................

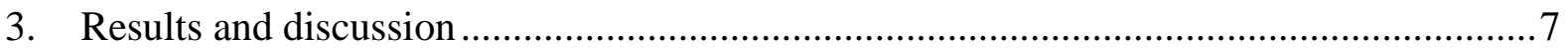

$3.1 \quad$ Characterization results...............................................................................

3.1.1 Elemental analysis, CO chemisorption and BET surface area..................................

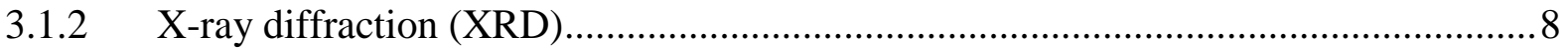

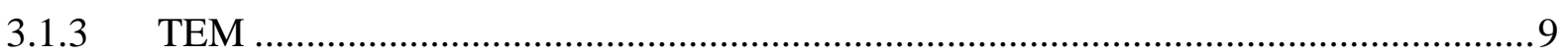

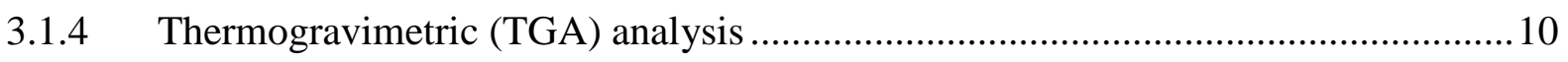

3.1.5 Pyridine adsorption studies (Py-FTIR) ……………………………………….... 11

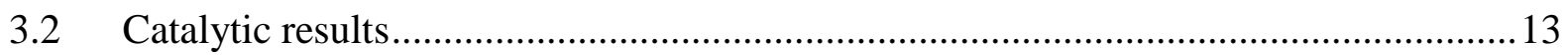

3.2.1 Deactivation of Beta and Pt-Beta catalysts ........................................................... 13

3.2.2 Regeneration of Beta and Pt-Beta catalysts ……………...................................... 14

3.2.3 Effect of regeneration on the yield of major products ..........................................15

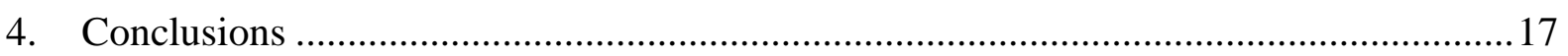

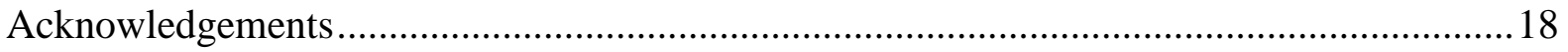

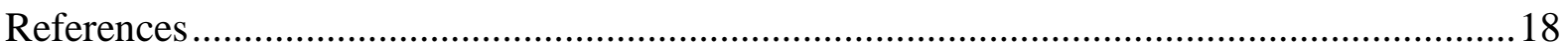




\title{
Effect of hydrogenative regeneration on the activity of Beta and Pt-Beta zeolites during the transalkylation of toluene with 1,2,4-trimethylbenzene
}

\author{
Faisal M. Almulla $*^{a}$, Vladimir I. Zholobenko ${ }^{c}$, Aleksander A. Tedstone $e^{b}$, Abdulrahman, bin \\ Jumah $^{b}$, Mohammed R., Aldossary ${ }^{a}$ and Arthur A. Garforth ${ }^{* b}$ \\ ${ }^{a}$ Research and Development Center, Saudi Aramco, Dhahran 31311, Saudi Arabia \\ ${ }^{\mathrm{b}}$ School of Chemical Engineering and Analytical Science, The University of Manchester, \\ M13 9PL, UK \\ ${ }^{\mathrm{c}}$ School of Chemical and Physical Sciences, Keele University, ST5 5BG, UK \\ KEYWORDS
}

Transalkylation, toluene, 1,2,4-trimethylbenzene, xylene, Beta, deactivation, regeneration

\begin{abstract}
:
Catalyst deactivation remains a main challenge in the transalkylation process. To develop a cost-effective catalyst, improving the regeneration characteristics of Beta and Pt-Beta catalysts was investigated. Both Beta and Pt-Beta catalysts were studied in transalkylation in the presence of hydrogen. The regeneration process was carried out using hydrogen for four cycles of operation (30 hours on stream per cycle). A Pt-Beta catalyst with enhanced regeneration and activity characteristic relative to the parent materials is presented, and found to be stable, with the activity fully restored by regeneration with hydrogen at $500{ }^{\circ} \mathrm{C}$. The activity of the parent Beta dropped gradually after each cycle suggesting that the hydrogen alone at $500{ }^{\circ} \mathrm{C}$ was insufficient in removing the coke formed during the reaction. The drop in activity was attributed to the disappearance of Brønsted acid sites over the spent Beta catalyst due to the growth of coke molecules trapped in the zeolite micropores leading to the formation of highly polyaromatic molecules blocking those active sites. This limitation can be effectively overcome by platinum addition which enhanced the removal of coke during the regeneration via hydrocracking.
\end{abstract}




\section{Introduction:}

Benzene, toluene, and xylene are fundamental synthetic starting materials for many aromatic derivatives such as polyesters, plastics and detergents. Xylenes ( $p$-, $m$ - and $o$-) have the greatest market demand with an increasing annual rate of 5-6\% [1]. The availability of surplus toluene and low value of $\mathrm{C}_{9}$ aromatics makes the transalkylation process an attractive method of making higher value aromatic compounds, principally xylenes [2-4]. Zeolites are used in aromatic transformation reactions due to their acidic properties and shape selectivity $[5,6]$. Large-pore three-dimensional zeolites were shown to be an active catalyst for the transalkylation process [7] whereas medium pore zeolites such as ZSM-5 $(<0.56 \mathrm{~nm})$ restricts the diffusion of $\mathrm{C}_{9}$ molecules $\left(>0.74 \mathrm{~nm}\right.$ ) limiting the conversion of $\mathrm{C}_{9}$ and the selectivity to xylene [8]. Zeolite Beta in particular was shown to have high activity and xylene yield [9]. Beta zeolite, first synthesised by Robert Wadlinger in 1967 [10], has a structure is comprised of three-dimensional intersecting channel system at 12-membered $\mathrm{T}$ atoms where the pore dimensions are $0.66 \times 0.67 \mathrm{~nm}$ for the straight channels and $0.56 \times 0.56 \mathrm{~nm}$ for sinusoidal channels [11]. The high thermal stability and strong acidity of zeolite Beta makes this catalyst an attractive candidate with increased application in the petrochemical industries, notably aromatic alkylation [12] and nitration of aromatic compounds [13]. Furthermore, the availability of surplus toluene and $\mathrm{C}_{9}$ aromatics due to reduction of aromatics (e.g. benzene, $\left.\mathrm{C}_{9}+\right)$ in the gasoline pool $[14,15]$ makes the transalkylation reaction a viable way to produce xylene.

It was demonstrated in that adding a small amount of noble metal $(\mathrm{Pt})$ reduced the coke precursors due to its hydrogenation/dehydrogenation functionality, leading to an increase in catalytic activity and stability [16]; the catalyst however eventually deactivated. To further evaluate the use of such catalysts in a simple fixed-bed reactor, the possibility of carrying out multiple regeneration cycles is required to evaluate the performance of the catalyst under such conditions. Catalyst deactivation is costly and therefore, enhancing the catalyst stability or regaining the catalytic activity of the catalyst while maintaining a simple reactor design becomes an essential task to enhance the profitability of the process $[17,18]$.

During catalytic hydrocarbon conversion processes, especially transalkylation, the acidity in zeolites is affected by the retention of carbonaceous compounds (coke) inside the pores or on the outer surface of the crystallite $[19,20]$. Catalyst deactivation, leads to the loss of activity with time-on-stream [21, 22]. Causes of catalyst deactivation includes: poisoning 
of the active sites, pore blockage due to coke build-up, metal sintering, and phase/morphology transformation [23]. This deactivation leads to the retention of the carbonaceous/coke materials inside and/or outside the pores of the crystallite [24]. It is important that the active sites (e.g. Brønsted, Lewis) are accessible to the reactant molecules to maintain the catalytic activity $[25,26]$.

The regeneration of zeolite catalysts may be performed by oxidising the coke deposition at elevated temperatures, typically $\geq 500{ }^{\circ} \mathrm{C}$ depending of the type of zeolite used [27], whereas the use of hydrogen as a carrier gas has also shown a positive effect in removing or reducing the formation of the coke deposited in the zeolite pores/cavities [28], unlike the coke deposited inside the zeolite pores ; external coke tends to be more volatile and is readily removed by hydrocracking.

Metals are commonly used, in the presence of zeolite, in the petrochemical industries such as reforming [29], hydrocracking [30] and alkane hydroisomerization [31]. Platinum $(\mathrm{Pt})$, in its reduced form, is the predominant precious metal used as active component in industrial processes due to its ability for hydrogen transfer, form thermal stable dispersions on catalytic supports, its catalytic activity in hydrogenation/dehydrogenation reactions and resistance to phase change [32].

In this work, the deactivation of zeolite Beta and Pt-Beta was further studied. The possibility of restoring the activity was investigated by regenerating the catalysts using hydrogen at $500{ }^{\circ} \mathrm{C}$ and ambient pressure. The change of crystalline structure and nature of acid sites over the fresh and regenerated catalysts was also examined. The type of coke deposited on the spent and regenerated catalysts was also identified.

\section{Experimental procedure}

\subsection{Materials}

Zeolite Beta was obtained from Zeolyst International in ammonium form (CPE814E). Tetra-amine platinum (II) chloride $\left(\mathrm{Pt}\left(\mathrm{NH}_{3}\right)_{4} \mathrm{Cl}_{2}\right)$, obtained from Sigma-aldrich (98 wt. \% purity) was used as the platinum source. The feed was an equal weight mixture of toluene (Fluka $>99.7 \%$ ) and 1,2,4-trimethylbenzene (1,2,4-TMB) (Sigma-aldrich >98.0\%), both chemicals were used as received. Hydrogen used in the feed, as carrier gas, was obtained 
from BOC (99.99 wt. \% purity). Air (> 99.99\% purity) used for calcining the zeolites was obtained from BOC.

\subsection{Catalyst preparation}

The zeolite was calcined in-situ under flowing air $\left(40 \mathrm{ml} \mathrm{min}^{-1}\right)$ at $500{ }^{\circ} \mathrm{C}$ at a ramping rate of $1.5{ }^{\circ} \mathrm{C} \mathrm{min}^{-1}$ to transform the ammonium form of the zeolite into its protonated form. Platinum was introduced into the zeolite after calcination by incipient wetness impregnation. The zeolite was mixed with the platinum salt $\mathrm{Pt}\left(\mathrm{NH}_{3}\right)_{4} \mathrm{Cl}_{2}$ in deionized water $(1 \mathrm{~g}: 10 \mathrm{ml}$ zeolite : solution ratio, $0.30 \mathrm{~mol} \mathrm{dm}^{-3}$ ) and stirred for $24 \mathrm{~h}$ at temperature of $65{ }^{\circ} \mathrm{C}$. The samples were then dried at $110{ }^{\circ} \mathrm{C}$ for $12 \mathrm{~h}$. An additional calcination step at $500{ }^{\circ} \mathrm{C}$ in flowing air $(40 \mathrm{ml}$ $\min ^{-1}$ ) for $8 \mathrm{~h}$ was carried out in-situ for the Pt-Beta.

\subsection{Catalyst characterization}

The crystallinity of the catalysts was characterized by X-ray diffraction (XRD, RigakuMiniflex). Coke deposition in the spent and regenerated catalysts was analysed using thermogravimetric analysis (Q5000-IR, TA Instruments). The amounts of Si, Al, and Pt in the catalysts were determined by HF digestion followed by inductively coupled plasma optical emission spectroscopy (ICP-OES). The distribution and size of the platinum within Beta catalyst was observed using high-angle annular dark-field (HAADF) imaging on a FEI F30 transmission electron microscope (TEM) operating at $300 \mathrm{kV}$ in STEM mode. The platinum dispersion and surface area were also determined using a Quantachrome ChemBET Pulsar TPR/TPD analyser. Pt-Beta was reduced at $450{ }^{\circ} \mathrm{C}$ for $1 \mathrm{~h}$ in flowing hydrogen at $40 \mathrm{ml} / \mathrm{min}$; then the adsorption of $\mathrm{CO}$ carried out at $-50{ }^{\circ} \mathrm{C}$ using pulses of $1 \% \mathrm{CO}$ in Argon (BOC). The Brønsted and Lewis acid sites of the fresh, spent and regenerated catalysts were carried out using transmittance FTIR measurements in the $4000-1200 \mathrm{~cm}^{-1}$ spectral range at $4 \mathrm{~cm}^{-1}$ resolution using a Thermo iS10 spectrometer. After the zeolite was dehydrated at $450{ }^{\circ} \mathrm{C}$, the temperature was reduced to $150{ }^{\circ} \mathrm{C}$ and pyridine was admitted into the vacuum transmittance cell in a stepwise manner until no changes in the spectra were observed. The saturated sample was then evacuated for $10 \mathrm{~min}$ at $150{ }^{\circ} \mathrm{C}$ to remove physically adsorbed pyridine and the FTIR spectrum was collected. 


\subsection{Catalyst testing}

The catalyst powder was pressed, crushed and sieved $(200-425 \mu \mathrm{m})$ prior to loading. Then, $1.0 \mathrm{~g}$ of the pressed catalyst was loaded into the reactor tube and placed between two layers of glass beads $(425-600 \mu \mathrm{m})$ using glass wool plugs. A stainless steel down-flow fixed bed reactor $(530 \mathrm{~mm}$ length $\times 10 \mathrm{~mm}$ ID) was used, surrounded by a three zone tubular furnace, with a type $\mathrm{K}$ thermocouple to measure the catalyst reaction temperature. The liquid feed was introduced to the reactor using HPLC pump, while air and hydrogen flows were controlled using gas mass flow controllers. The liquid and hydrogen feeds were premixed prior to entering the reactor and a back-pressure regulator controlled the system pressure.

The catalyst was activated by increasing the temperature of the reactor to $500{ }^{\circ} \mathrm{C}$ at 1.5 ${ }^{\circ} \mathrm{C} / \mathrm{min}$ ramp and sustained for $8 \mathrm{~h}$ under flowing air $\left(40 \mathrm{ml} \mathrm{min}^{-1}\right)$. The temperature was then reduced and after reaching $150{ }^{\circ} \mathrm{C}$, the gas flow was switched to hydrogen $\left(70 \mathrm{ml} \mathrm{min}^{-1}\right)$ for 2 $\mathrm{h}$ and the temperature was increased to the reaction temperature at a ramping rate of 2 ${ }^{\circ} \mathrm{C} / \mathrm{min}$. The feed was then introduced to the unit where hydrogen was continually fed into the reactor during the test.

The transalkylation testing was conducted for Time-On-Stream (TOS) $=30 \mathrm{~h}$. After this, the spent catalyst was regenerated in situ for $16 \mathrm{~h}$ in hydrogen flow $\left(70 \mathrm{ml} \mathrm{min}^{-1}\right)$, by increasing the temperature to $500{ }^{\circ} \mathrm{C}$ and reducing pressure to ambient. The regenerated catalyst was tested again under the same reaction conditions. The regeneration process was repeated for three cycles, giving a total of four deactivation cycles. Each catalytic experiment was carried out at $\mathrm{T}=400{ }^{\circ} \mathrm{C}, \mathrm{P}=10 \mathrm{bar}, \mathrm{H}_{2} / \mathrm{HC}=4(\mathrm{~mol} / \mathrm{mol})$, and the WHSV value of $5 \mathrm{~h}^{-1}$.

The overall conversion (1,2,4-TMB + toluene) and xylenes yield were calculated using the following equations where $\mathrm{m}_{\mathrm{Tol}}$ and $\mathrm{m}_{\mathrm{TMB}}$ are the weight of toluene and 1,2,4-TMB, respectively.

$$
\begin{aligned}
& \text { Conversion }=\frac{\left(\mathrm{m}_{\mathrm{Tol}}+\mathrm{m}_{\mathrm{TMB}}\right) \text { in }-\left(\mathrm{m}_{\mathrm{Tol}}+\mathrm{m}_{\mathrm{TMB}}\right) \text { out }}{\left(\mathrm{m}_{\mathrm{Tol}}+\mathrm{m}_{\mathrm{TMB}}\right) \mathrm{in}} \times 100 \\
& \text { Xylenes yield }=\frac{\text { Total xylenes in product mixture }}{\left(\mathrm{m}_{\mathrm{Tol}}+\mathrm{m}_{\mathrm{TMB}}\right) \text { feed }} \times 100
\end{aligned}
$$




\subsection{Feed and product analysis}

The feed and product samples were analysed using a HP 6890 Gas Chromatograph fitted with a Stabilwax Capillary Column $(30 \mathrm{~m} \times 0.32 \mathrm{~mm}$ i.d. $\times 1.0 \mu \mathrm{m}$ film thickness $)$ using a flame ionization detector (FID).

\section{Results and discussion}

\subsection{Characterization results}

\subsubsection{Elemental analysis, CO chemisorption and BET surface area}

The elemental composition of tested catalysts is shown in Table 1 where the $\mathrm{Si} / \mathrm{Al}$ ratios were found to be in good agreement with those quoted by the manufacturer. The platinum loading was found to be within the targeted amount allowing for measurement error (typically $\pm 10 \mathrm{ppm}$ ). A slight decrease in both the external and the micropore areas was observed and can be attributed to the formation of platinum agglomerates on the zeolite. Since the average particle size of platinum agglomerates is larger than the pore dimension of the zeolite, it is expected that most of the platinum is located on the external surface of the catalyst. The chemisorption results for Pt-Beta showed a high platinum dispersion of $82 \%$ (example of EPS mapping is shown in Figure 1), with an average particle size of $1.2 \mathrm{~nm}$ and metallic surface area was estimated to be equal to $0.16 \mathrm{~m}^{2} / \mathrm{g}$.

Table 1: Characterization results of the catalysts used in this study.

\begin{tabular}{|c|c|c|c|c|c|c|c|c|}
\hline \multirow{2}{*}{ Catalyst } & \multirow{2}{*}{$\mathrm{Si} / \mathrm{Al}$} & \multirow{2}{*}{$\begin{array}{c}\mathrm{Pt} \\
\text { (wt. \%) }\end{array}$} & \multicolumn{2}{|c|}{ BET surface area $\left(\mathrm{m}^{2} / \mathrm{g}\right)$} & \multirow{2}{*}{$\begin{array}{c}\text { Pore } \\
\text { volume } \\
\left(\mathrm{cm}^{3} / \mathrm{g}\right)\end{array}$} & \multirow{2}{*}{$\begin{array}{c}\mathrm{Pt} \\
\text { dispersion } \\
(\%)\end{array}$} & \multirow{2}{*}{$\begin{array}{c}\mathrm{Pt} \\
\text { surface } \\
\text { area } \\
\left(\mathrm{m}^{2} / \mathrm{g}\right)\end{array}$} & \multirow{2}{*}{$\begin{array}{l}\text { Pt avg. } \\
\text { particle size } \\
\quad(\mathrm{nm})\end{array}$} \\
\hline & & & $\begin{array}{c}\text { micropore } \\
\text { area }\end{array}$ & $\begin{array}{c}\text { external } \\
\text { area }\end{array}$ & & & & \\
\hline Beta & 12.7 & - & 309 & 222 & 0.18 & - & - & - \\
\hline Pt-Beta & 13 & 0.08 & 265 & 192 & 0.13 & 82 & 0.16 & 1.2 \\
\hline
\end{tabular}




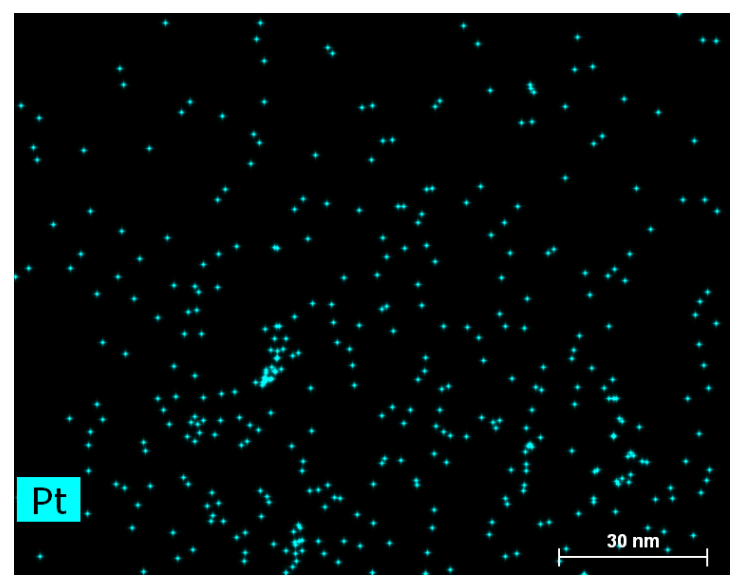

Figure 1: EDS mapping of the Pt-Beta zeolite.

\subsubsection{X-ray diffraction (XRD)}

The crystallinity of zeolite Beta was examined before and after regeneration process (four-cycles). The crystallinity of both fresh hydrated and regenerated zeolite Beta samples was determined by comparing the peak intensities ( $2 \Theta$ range from 2.5 to $75^{\circ}$ ) with regenerated catalyst after the fourth cycle. The regenerated sample showed no structural damage confirming the thermal stability of the tested zeolite (Figure 2). The relative crystallinity was calculated to be $95 \%$ based on fresh Beta catalyst using equation 3, thus highlighting the high thermal stability of the zeolite Furthermore, there was no observable change in the XRD patterns for the Pt-Beta catalyst indicating that the platinum loading did not affect the zeolite's structural properties.

Relative crystallinity $(\%)=\frac{\sum_{i=1}^{n} \text { Peak Intensity of the regenerated catalyst }}{\sum_{i=1}^{n} \text { Peak Intensity of the parent catalyst }}$ 


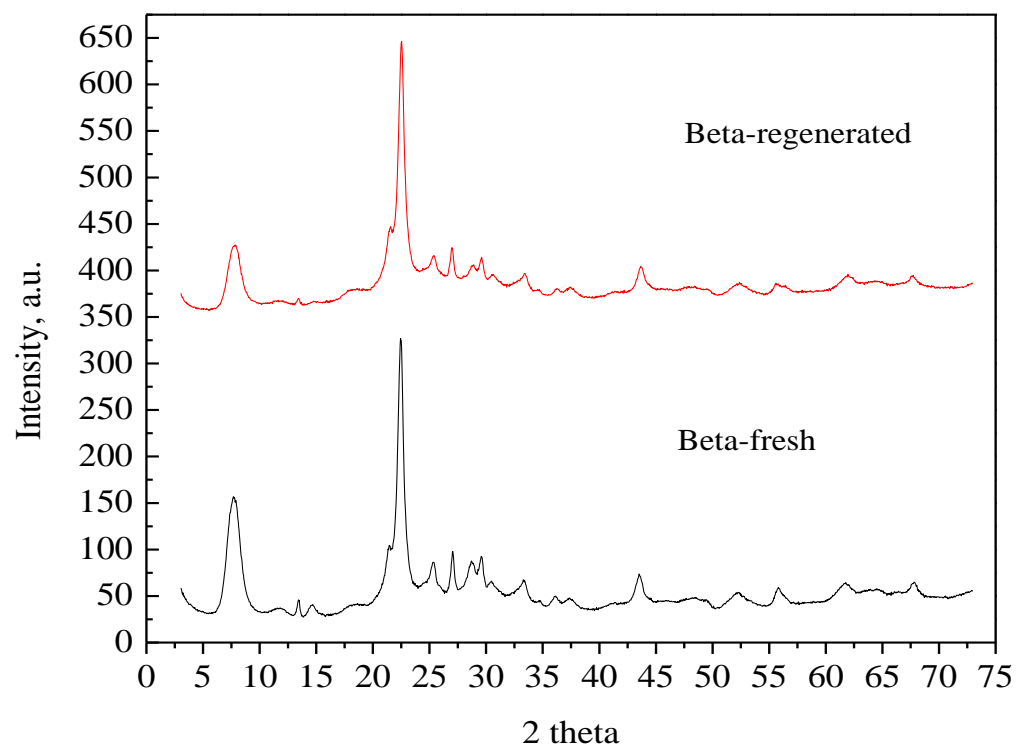

Figure 2: X-ray diffraction patterns of zeolite Beta before and after regeneration $\left(4^{\text {th }}\right.$ cycle).

\subsubsection{TEM}

TEM bright field images of fresh, spent and regenerated Pt-Beta catalysts are shown in Figure 3. The average Pt particle size is between $1.0-1.5 \mathrm{~nm}$ in the three catalysts. Metal sintering (increasing metal particle size) is a common issue occurring during high reaction temperatures and hence, affect the catalyst activity [33]. However, the use of very low levels of metal helps to avoid sintering and assist in maintaining the catalyst activity during multiple regeneration cycles. Since the intra-crystalline pore diameter of zeolite Beta is $0.67 \mathrm{~nm}$, which is lower than the average platinum particle size, the platinum must be predominantly located on the external crystalline surfaces of the zeolite.
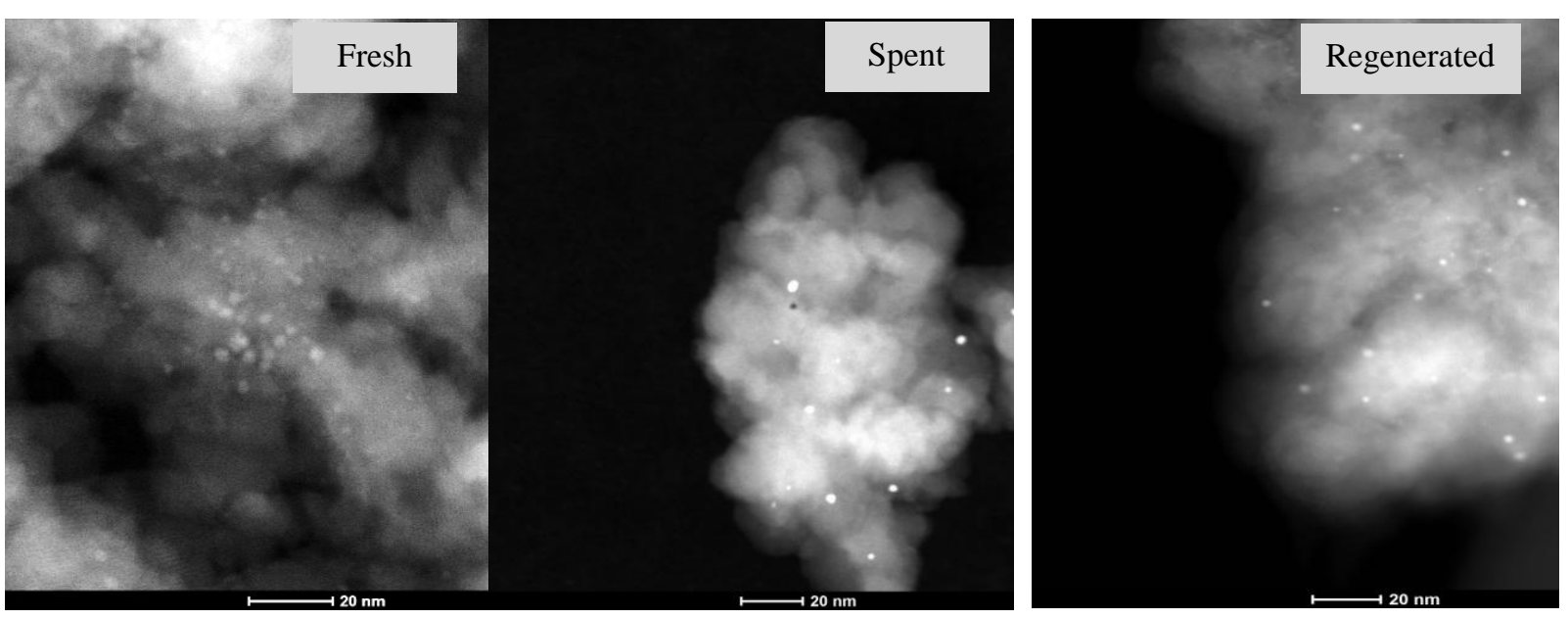

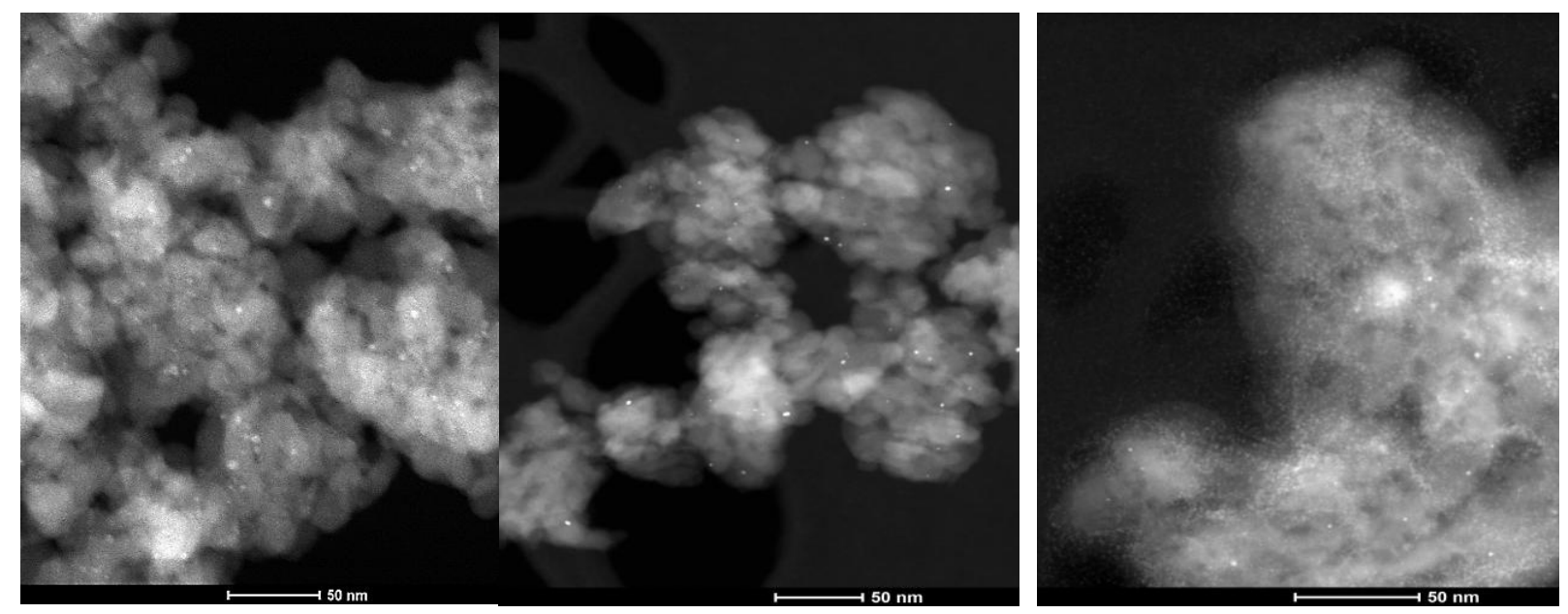

Figure 3: STEM-HAADF images of fresh, spent and regenerated Pt-Beta catalysts. Bright spots represent Pt clusters.

\subsubsection{Thermogravimetric (TGA) analysis}

The calcination of the tested zeolites was studied by monitoring the weight loss using TGA (up $600{ }^{\circ} \mathrm{C}$ ). The weight loss occurs due to the evaporation of volatile components, physically adsorbed water, chemically adsorbed water and the oxidation of carbonaceous compounds. The typical weight loss curves plotted against time for the spent and regenerated catalysts (Beta and Pt-Beta) are shown in supporting information.

The initial weight loss commencing typically at a temperature below $200{ }^{\circ} \mathrm{C}$ can be attributed to the water desorption from zeolites [34], and this can vary depending on zeolite framework with weight loss up to $20 \%[35,36]$. Typically, Beta and Pt-Beta catalysts had a weight loss of $8 \%$. The amount of weight loss (coke \%) of spent and regenerated catalysts are summarised in Table 2. The introduction of low levels of platinum clearly reduced the coke formation on the zeolite by about $40 \%$ in the first cycle and by $65 \%$ in the $4^{\text {th }}$ cycle. This can be attributed to the role of platinum in removing the coke precursors by hydrocracking during the reaction cycles. This result also highlights the role platinum plays in the removal of coke during the regeneration process. Pt-Beta showed a significant reduction of the coke by about $43 \%$ while Beta catalyst retained most of the coke even after regeneration.

Table 2: The coke deposition content over spent and regenerated Beta/Pt-Beta catalysts.

\begin{tabular}{lcc}
\hline Catalyst & Spent $\left(1^{\text {st }}\right.$ cycle $)$ & Regenerated $\left(4^{\text {th }}\right.$ cycle $)$ \\
\hline Beta & 9.06 & 8.81 \\
Pt-Beta & 5.50 & 3.11 \\
\hline
\end{tabular}




\subsubsection{Pyridine adsorption studies (Py-FTIR)}

The acid sites were determined using the intensity of the $\mathrm{Py}-\mathrm{H}^{+}$and $\mathrm{Py}-\mathrm{L}$ peaks at 1455 and $1545 \mathrm{~cm}^{-1}$ respectively to study the acidity profiles of the fresh, spent and regenerated catalysts. The acidity measurements indicate that the total acidity of the zeolite was not changed after the introduction of platinum $(0.94$ to $0.95 \mathrm{mmol} / \mathrm{g})$ while the ratio of Brønsted and Lewis acidity was significantly altered with Pt-Beta having a lower B/L ratio. This can be attributed to the dealumination process during the platinum addition which generates extraframework aluminium (EFAL) species due to the acidity of the platinum solution and the moist environment of during the dehydration of the zeolite which can further generate EFAL specias through steaming [37] thus reducing the Brønsted acidity while increasing the Lewis acid sites.

Comparing the fresh and regenerated catalysts shows a significant reduction in acidity of the Beta catalyst by about $47 \%$ in while the Pt-Beta catalyst maintained most its acidic sites (reduction of about $15 \%$ ). Platinum addition clearly reduced the coke build-up and availed more acidic sites for the reaction after regeneration (Figure 4). Comparing the acidity profiles of Beta catalyst before and after four cycles of regeneration shows that the coke selectively built-up on the Brønsted acid sites as the Brønsted acidity was reduced by more than two thirds its initial value. This is in agreement with the work of Matsuda et. al [38] and Zaiku et. al [39] who reported that the transalkylation reaction is mainly promoted by Brønsted acidity. The Pt-Beta catalyst retained most of its Brønsted acidity after regeneration, only losing about $12 \%$ while the Lewis acidity was reduced further by about $16 \%$. Higher hydrogen pressure during the regeneration or increasing the regeneration temperature could completely restore the acidic sites after the platinum introduction. 

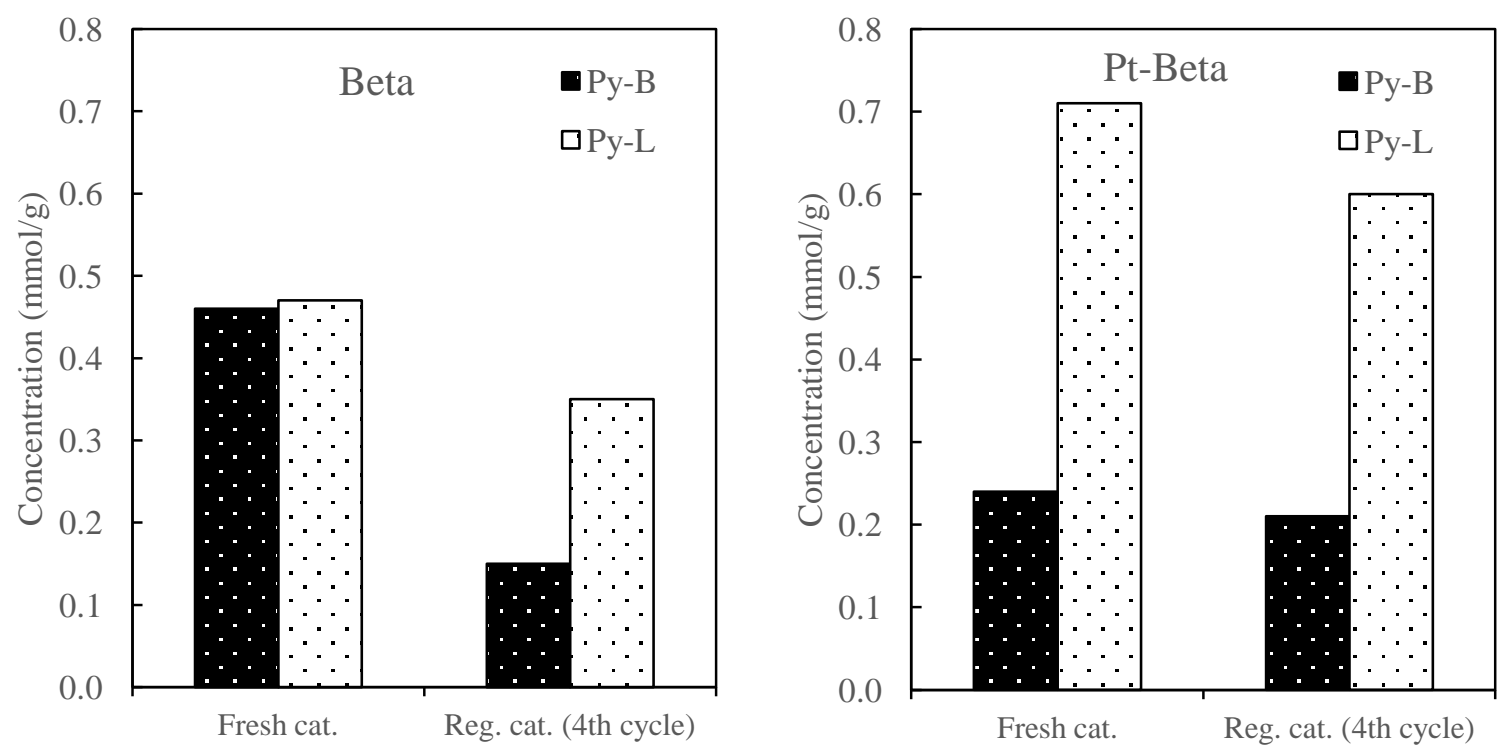

Figure 4: The concentration of Brønsted acid sites (Py-B) and Lewis acid sites (Py-L) over zeolites the fresh and regenerated catalysts.

The nature of the hydrocarbon deposited on the deactivated Beta zeolite was inspected using FTIR spectra in the range of $3700-1400 \mathrm{~cm}^{-1}$ in Figure 5. The bands located between 3000 and $3200 \mathrm{~cm}^{-1}$ are attributed to $\mathrm{C}-\mathrm{H}$ bonds in aromatic deposits, while the band at 1590 $\mathrm{cm}^{-1}$ is attributed to $\mathrm{C}=\mathrm{C}$ bonds in polyaromatic hydrocarbons (hard coke) [40]. It was also observed that the bands near $3000 \mathrm{~cm}^{-1}$ are an indication of $-\mathrm{CH}_{2}$ and $-\mathrm{CH}_{3}$ groups of paraffinic compounds. The bands between 1370 and $1500 \mathrm{~cm}^{-1}$ are commonly associated to paraffinic oligomers (soft coke) [41].

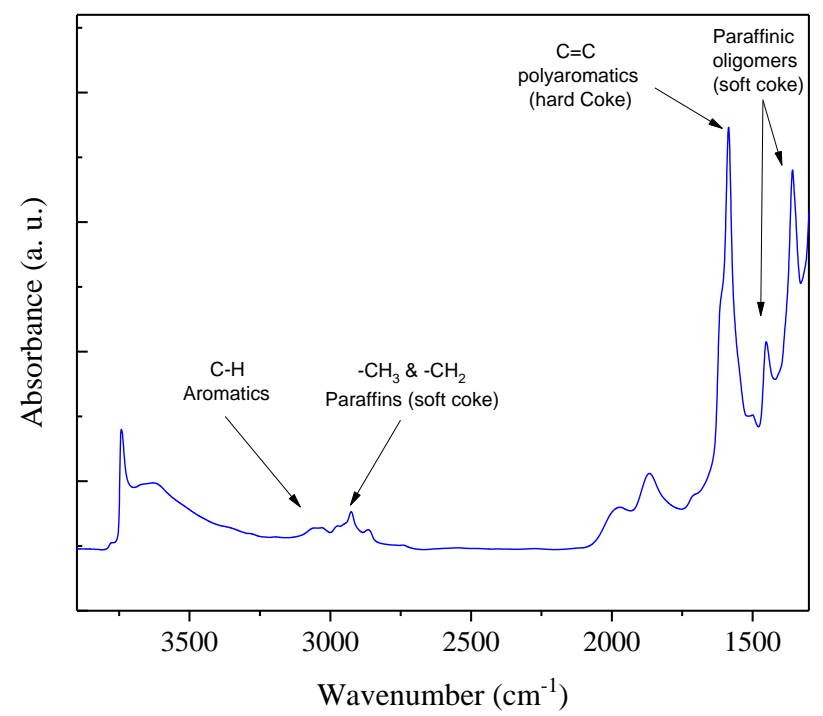

Figure 5: FTIR spectra of the deactivated Beta catalyst in the range of $3700-1400 \mathrm{~cm}^{-1}$ highlighting the bands associated with different types of coke present on the zeolite. 
The difference between the IR spectrum of the deactivated and the fresh Beta catalyst is presented in Figure 6. The spectra of the catalysts suggests that the deactivation is mainly related to the presence of bulky polyaromatic coke at the active sites. The regenerated Pt-Beta catalyst showed the removal of most of the coke species while the Beta catalyst retained the coke highlighting the important role of platinum during the regeneration. Within the Pt-Beta catalyst, the branched alkyl groups (soft coke) were completely removed whereas the intensity of the polyaromatic peak was reduced significantly, indicating the presence of hard coke. This observation can explain the loss of acidic sites after the regeneration as shown in Figure 4 since some of the zeolite's pores were inaccessible to the base pyridine due to the presence of the polyaromatic hydrocarbons.
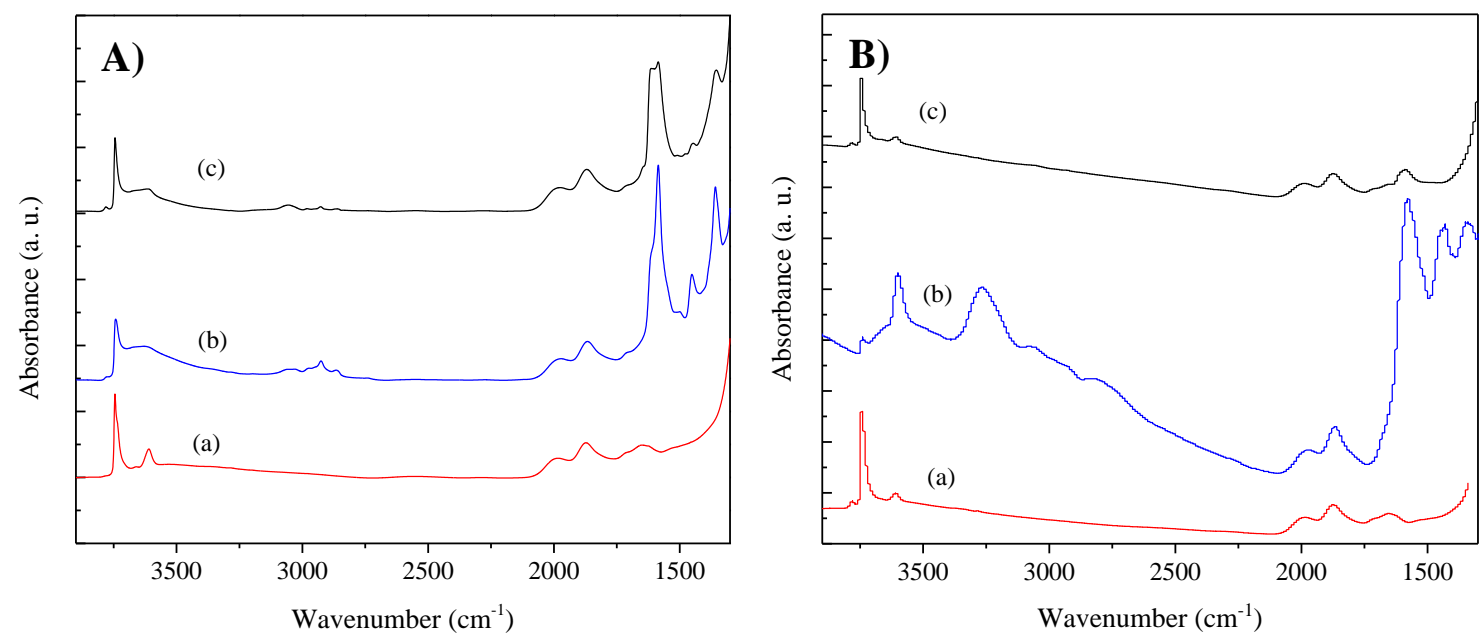

Figure 6: FTIR spectra of (a) fresh, (b) spent/deactivated after $30 \mathrm{~h}$ TOS $\left(1^{\text {st }}\right.$ cycle $)$ and (c) regenerated $\left(4^{\text {th }}\right.$ cycle $)$ A) Beta B) Pt-Beta catalysts.

\subsection{Catalytic results}

\subsubsection{Deactivation of Beta and Pt-Beta catalysts}

The catalyst deactivation behaviour was clearly observed over the Beta catalyst where the feed conversion and xylenes yield dropped dramatically up to TOS $=30 \mathrm{~h}$, and after that the deactivation was less pronounced after 20-25 $\mathrm{h}$ from starting the test. However, the deactivation was much reduced, and dropped only by about 2 wt. \%, at similar TOS when using Pt-Beta (Figure 7). Based on this result, the regeneration step of the two catalysts was examined after $30 \mathrm{~h}$ of operation to control this rapid deactivation and examine the possibility of re-activating zeolite Beta for several cycles. 

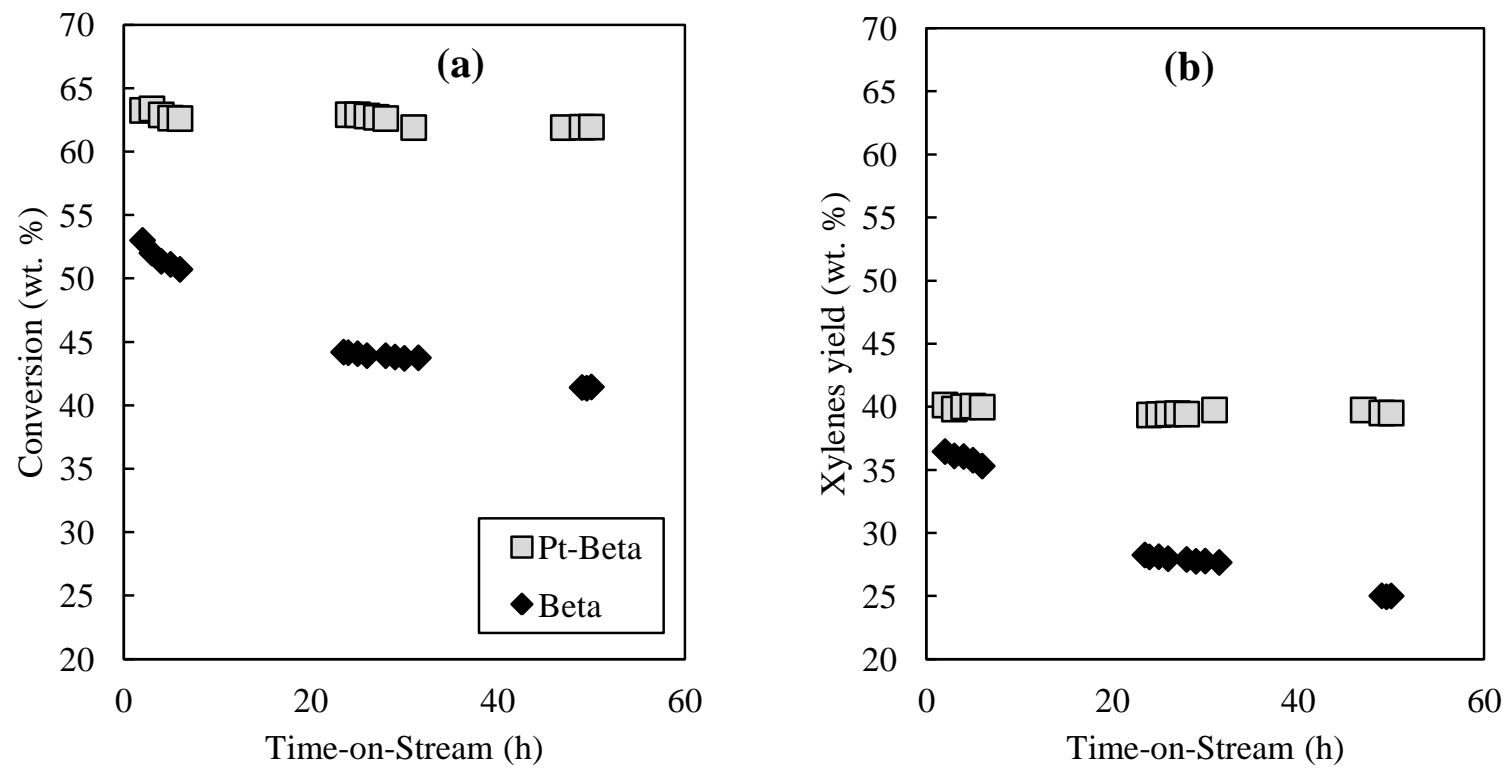

Figure 7: Deactivation behaviour showing the conversion (a) and xylenes yield (b) with time over Beta/Pt-Beta catalysts. $\mathrm{T}=400{ }^{\circ} \mathrm{C}, \mathrm{P}=10 \mathrm{bar}, \mathrm{H}_{2} / \mathrm{HC}=4$ and $\mathrm{WHSV}=5 \mathrm{~h}^{-1}$.

\subsubsection{Regeneration of Beta and Pt-Beta catalysts}

Multiple related processes, such as toluene disproportionation, reported that elevated hydrogen pressure is necessary for the removal of coke precursors and coke deposits which can block the zeolite micropores thus leading to catalyst deactivation $[42,43]$. The restoration of catalyst activity was demonstrated for $30 \mathrm{~h}$ in the transalkylation unit, regenerated at 500 ${ }^{\circ} \mathrm{C}$, and then re-tested in each cycle, up to four cycles.

The catalytic conversion of both catalysts was plotted versus the TOS as shown in Figure 8 , where the activity of Pt-Beta was fully restored by regeneration. The parent Beta catalyst did not maintain its activity and continuously lost its activity after each regeneration cycle. It was observed that the deactivation rate increased gradually after each regeneration step; the conversion dropped only after the first cycle, from 44 to $40 \mathrm{wt}$. \%, and then the conversion was maintained at a similar level for the following two cycles.

Both catalysts showed different levels of activity restoration, showing the effect of hydrogenation functionality when using a noble metal, even at very low levels, helping increase the coke hydrocracking; thus removing these coke precursors from blocking the catalyst active sites. 


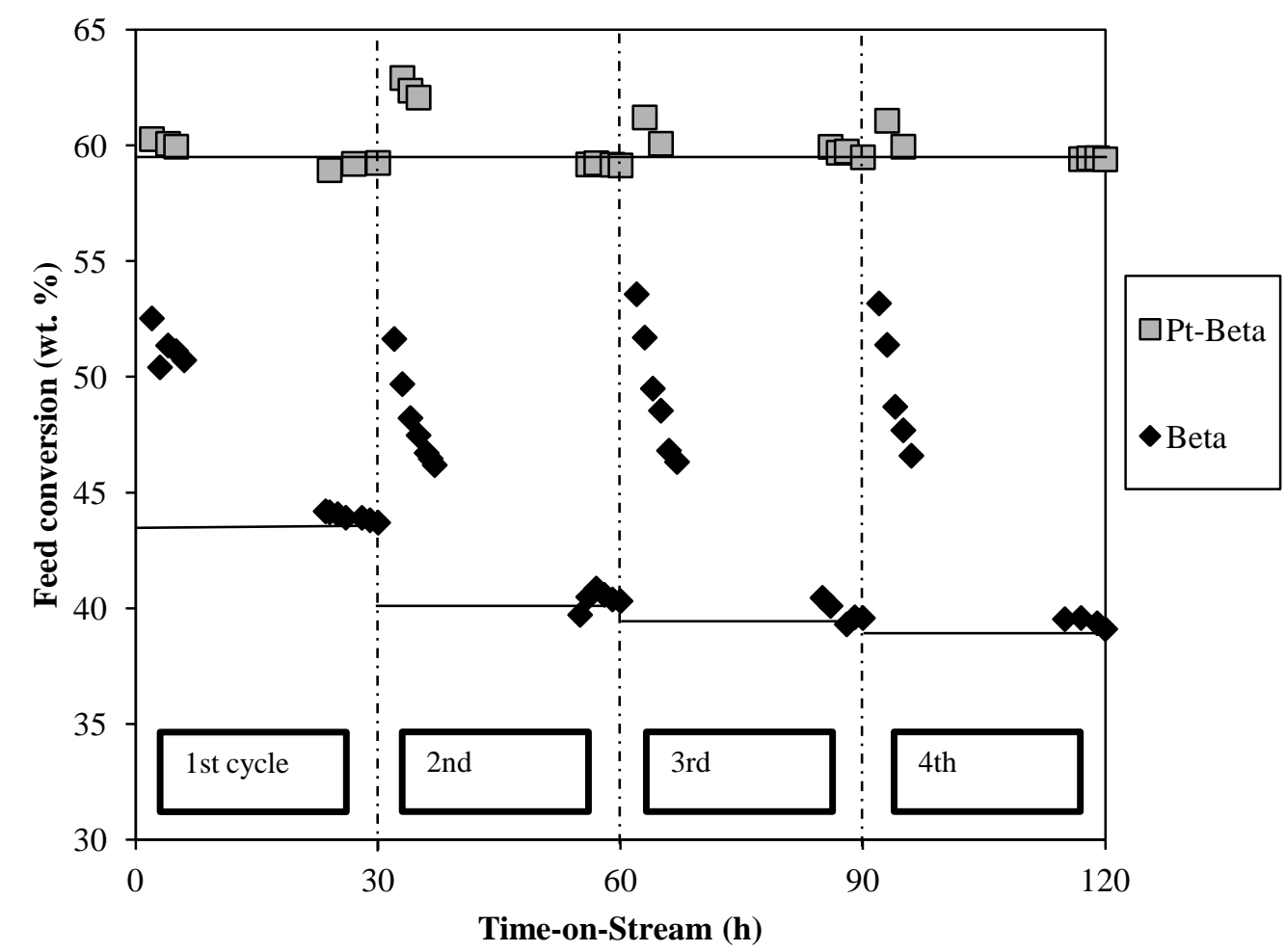

Figure 8: Overall feed conversion within four regeneration cycles at $30 \mathrm{~h}$ TOS for each (at a time indicated in $\mathrm{x}$-axis) over $\mathrm{H}$-beta and Pt-beta $(800 \mathrm{ppm}) . \mathrm{T}=400{ }^{\circ} \mathrm{C}, \mathrm{P}=10 \mathrm{bar}, \mathrm{H}_{2} / \mathrm{HC}=4$ and $\mathrm{WHSV}=5 \mathrm{~h}^{-1}$.

\subsubsection{Effect of regeneration on the yield of major products}

The yield of the major products (benzene, xylenes, trimethylbenzenes (1,3,5- and 1,2,3TMBs) and tetramethylbenzenes (TeMBs)) before and after the regeneration cycles of both catalysts used for $30 \mathrm{~h}$ is shown in Figure 9. The changes in the products were noticeable over parent Beta between each cycle, whereas no significant changes were observed over PtBeta-in all reactivated cycles. For example, the xylenes yield, at TOS $=30 \mathrm{~h}$, dropped from 28 to $22 \mathrm{wt}$. $\%$ from the $1^{\text {st }}$ to $2^{\text {nd }}$ regeneration cycle and then remained at similar yields at the following two cycles. However, in Pt-Beta, the xylenes yield was equal to $38 \mathrm{wt} \%$ at all four cycles. The reduction in xylenes yield over Beta can be explained by the influence of catalyst deactivation on limiting other side reactions (e.g. toluene disproportionation), this is also apparent in benzene yield which shows a similar deactivation trend. 
(a) Beta

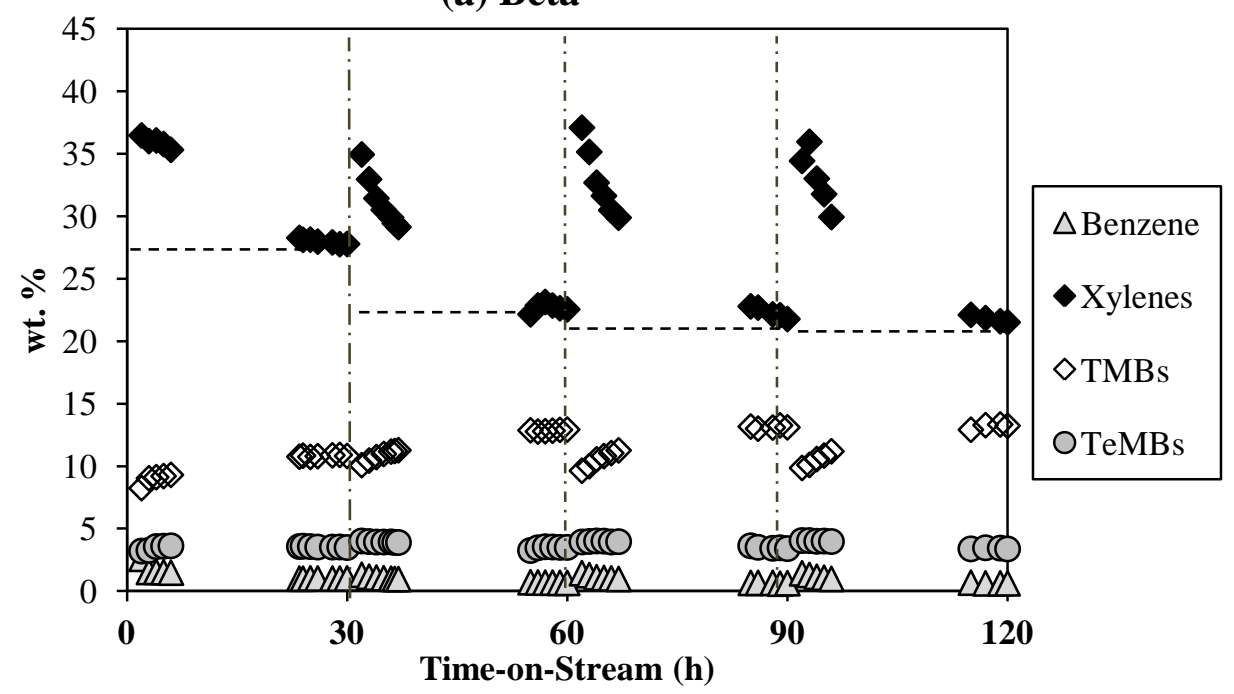

(b) Pt-Beta

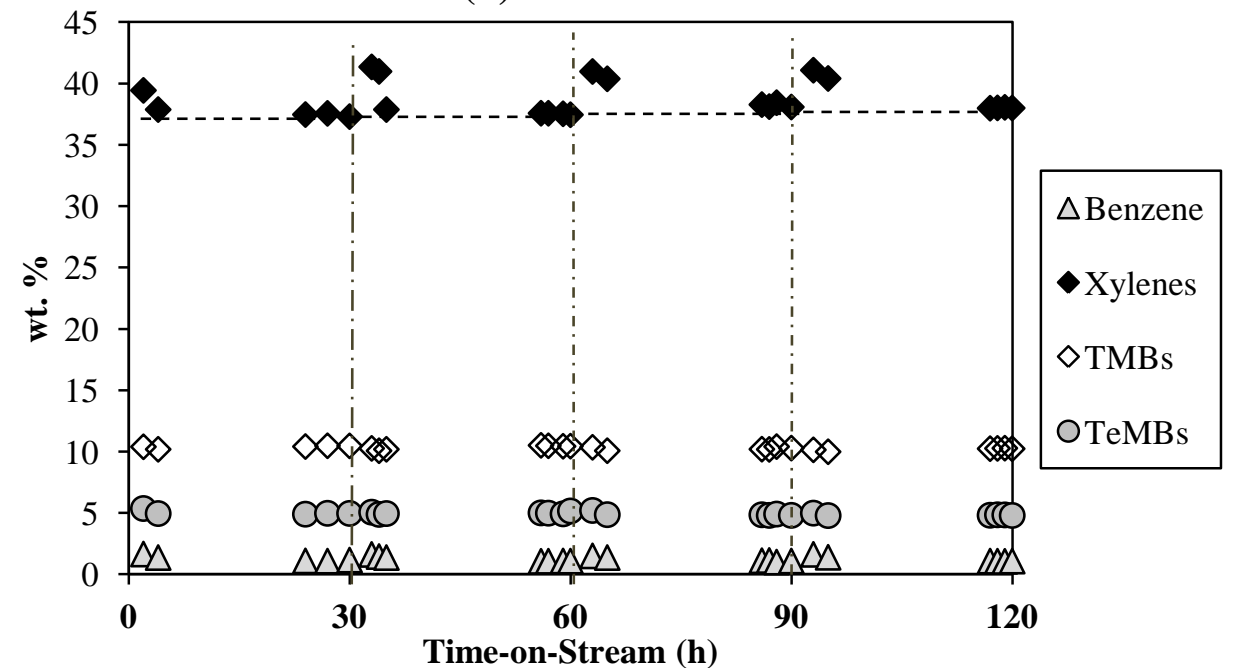

Figure 9: Conversion and product distribution on (a) Beta and (b) Pt-Beta within four transalkylation/regeneration cycles (at the times indicated by the vertical dotted lines, the catalyst was regenerated at $500{ }^{\circ} \mathrm{C}$ ). $\mathrm{T}=400{ }^{\circ} \mathrm{C}, \mathrm{P}=10$ bar, $\mathrm{H}_{2} / \mathrm{HC}=4$ and WHSV $=5 \mathrm{~h}^{-1}$.

As the disproportionation and transalkylation reactions are less favoured due to a loss of strong acid sites through deactivation, the amount of TMB in the products increases (due to isomerisation) with time $(30 \mathrm{~h})$. The yield of TeMB isomers remained constant at each cycle on both catalysts ( 3.5 and 5 wt. \% over Beta and Pt-Beta, respectively), suggesting that the regeneration had no effect on the disproportionation of 1,2,4-TMB. Figure 10 shows a comparison of the major products yielded at $\mathrm{TOS}=30 \mathrm{~h}$ over both catalysts before regeneration. 

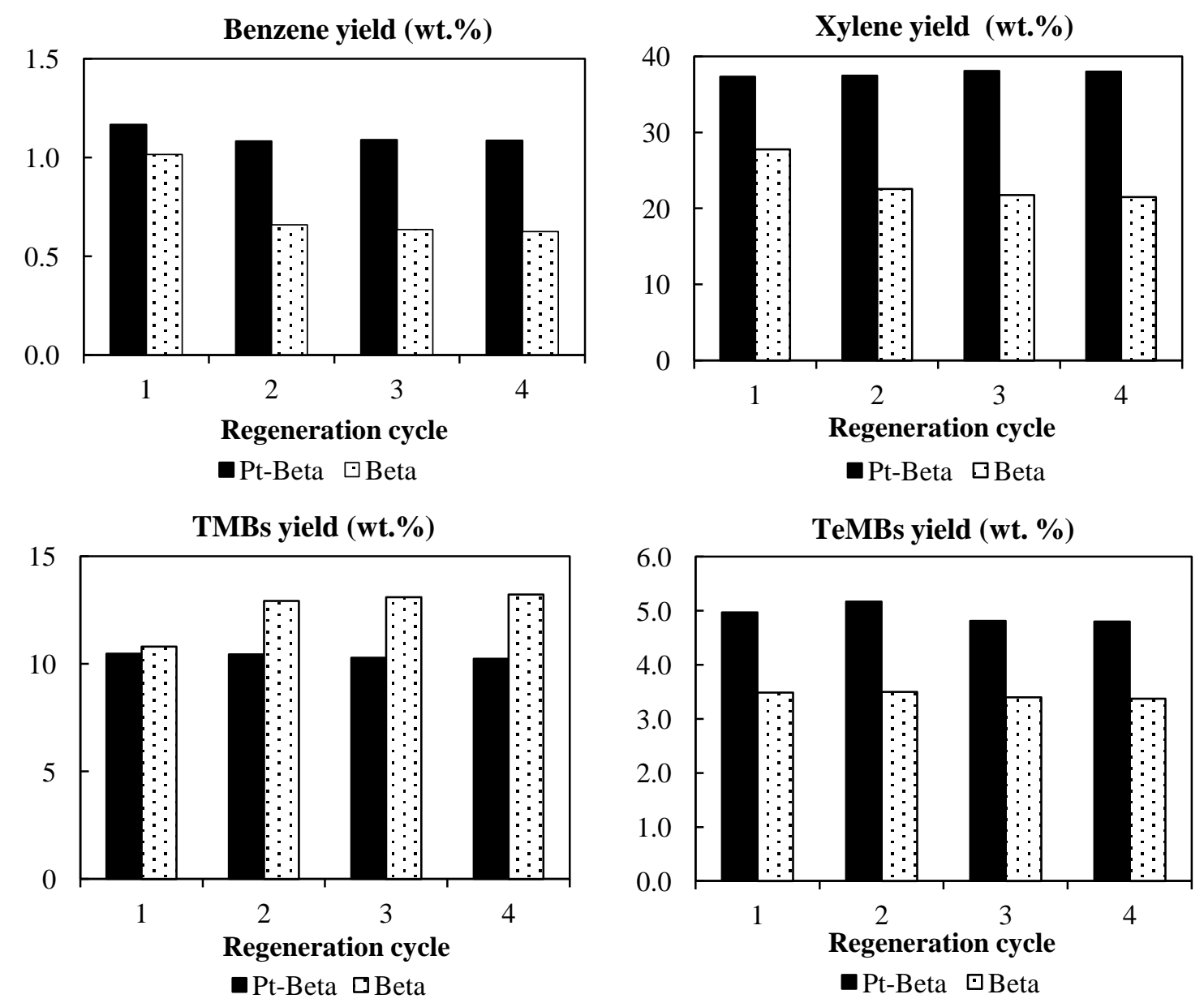

Figure 10: Comparison of major products yielded at $\mathrm{TOS}=30 \mathrm{~h}$ over Beta and Pt-Beta $(800 \mathrm{ppm})$ for four cycles, $\mathrm{T}=$ $400{ }^{\circ} \mathrm{C}, \mathrm{P}=10$ bar, $\mathrm{H}_{2} / \mathrm{HC}=4$ and $\mathrm{WHSV}=5 \mathrm{~h}^{-1}$.

\section{Conclusions}

Utilizing very low levels of platinum, the activity of zeolite Beta can be completely restored for the transalkylation reaction. at $\mathrm{T}=500{ }^{\circ} \mathrm{C}$ and under low pressures of hydrogen as shown in Figure 11 which summarises the $30 \mathrm{~h}$ TOS data in Figure 8 highlighting the possibility of a transalkylation process utilizing semi-regenerative fixed bed reactors. However, the activity of unmodified zeolite Beta dropped gradually after each regeneration cycle, demonstrating the benefit of Pt impregnation in preserving the catalyst. The decrease in the activity of unmodified zeolite Beta resulted in an increase in the formation TMB isomers and a decrease in benzene content. This led to pore blockage in the acid sites, in particular the Brønsted acid sites.

It was shown from the FTIR results that the regeneration of Beta resulted in removing the branched group (soft coke), whereas the polyaromatic (hard coke) was only partially removed under such regeneration conditions. 
The XRD patterns showed that there was no damage in the zeolite structure even after regenerating the catalyst over four cycles ( $30 \mathrm{~h}$ TOS per cycle). The removal of coke deposition on the spent catalysts was significantly higher on the Pt-Beta catalyst after the regeneration step when hydrogen only was used.

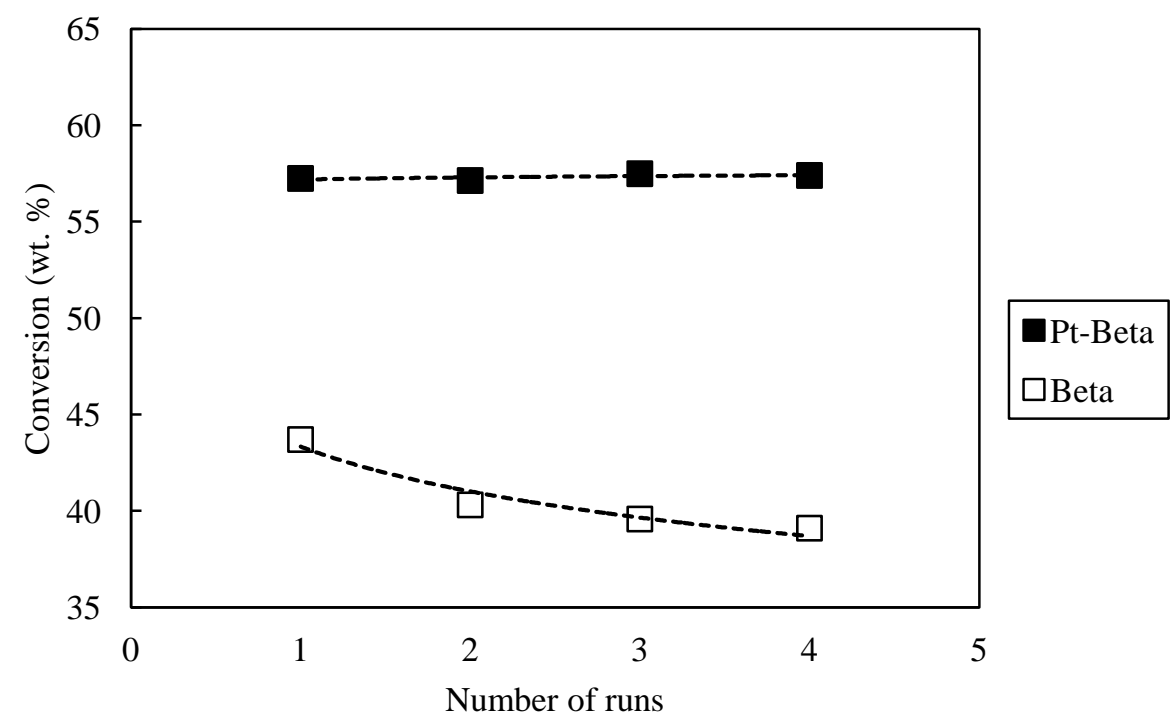

Figure 11: Conversion of the Beta/Pt-Beta catalysts (wt. \%) at $\mathrm{TOS}=30 \mathrm{~h}$ versus the number of regenerations. $\mathrm{T}=$ $400{ }^{\circ} \mathrm{C}, \mathrm{P}=10 \mathrm{bar}, \mathrm{H}_{2} / \mathrm{HC}=4$ and WHSV $=5 \mathrm{~h}^{-1}$.

\section{Acknowledgements}

The authors would like to acknowledge the support from Saudi Aramco.

\section{References}

[1] Y. Khabzina, C. Laroche, J. Perez-Pellitero, D. Farrusseng, Microporous Mesoporous Mater., 247 (2017) 52-59.

[2] S.A. Ali, A.M. Aitani, C. Ercan, Y. Wang, S. Al-Khattaf, Chem. Eng. Res. Des. 89 (2011) $2125-2135$.

[3] A.M. Aitani, A.M. Ali, S.M. Waziri, S. Al- Khattaf, Chem. Eng. Technology, 33 (2010) 1193-1202.

[4] S.A. Ali, A.M. Aitani, J. Čejka, S.S. Al-Khattaf, Catal. Today, 243 (2015) 118-127.

[5] H.S. Cerqueira, P. Ayrault, J. Datka, M. Guisnet, Microporous Mesoporous Mater., 38 (2000) 197-205.

[6] M.T. Portilla, F.J. Llopis, C. Martinez, S. Valencia, A. Corma, Appl. Catal. A Gen., 393 (2011) 257-268. 
[7] J. Das, Y.S. Bhat, A.I. Bhardwaj, A.B. Halgeri, Appl. Catal. A Gen., 116 (1994) 71-79.

[8] X.J. Cheng, X.S. Wang, H.Y. Long, Microporous Mesoporous Mater., 119 (2009) 171175.

[9] A. Krejc1, S. Al-Khattaf, M.A. Ali, M. Bejblova, J. Cejka, Appl. Catal. A Gen., 377 (2010) 99-106.

[10] R.L. Wadlinger, G.T. Kerr, E.J. Rosinski, US Patent 3,308,069 (1967).

[11] Ch. Baerlocher, W.M. Meier, D.H. Olson, Atlas of Zeolite Framework Types, Elsevier, Amsterdam, (2001).

[12] G. Bellussi, G. Pazzuconi, C. Perego, G. Girotti, G. Terzoni, J. Catal., 157 (1995) 227234.

[13] K. Smith, A. Musson, G.A. DeBoos, Chem. Commun., (1996) 469-470.

[14] V.J. Margarit, M.T. Portilla, M.T. Navarro, R. Abudawoud, I.M. Al-Zahrani, S. Shaikh, C. Martinez, A. Corma, Appl. Catal. A Gen., 581 (2019) 11-22.

[15] K. Mokoena, M.S. Scurrell, Microporous Mesoporous Mater., 241 (2017) 28-35.

[16] F.M. Almulla, V.I. Zholobenko, P.I. Hill, S. Chansai, A.A. Garforth, Ind. Eng. Chem. Res., 56 (2017) 9799-9808.

[17] M. Guisnet, P. Magnoux, Catal. Today, 36 (1997) 477-483.

[18] S.M. Domingues, J.M. Britto, A.S. De Oliveira, A. Valentini, P. Reyes, J.M. David, M.C. Rangel, Stud. Surf. Sci. Catal, 139 (2001) 45-42.

[19] X.H. Ren, M. Bertmer, S. Stapf, D.E. Demco, B. Blümich, C. Kern, A. Jess, Appl. Catal. A Gen., 228 (2002) 39-52.

[20] T.-C. Tsai, S.-B. Liu, I. Wang, Appl. Catal. A Gen., 181 (1999) 355-398.

[21] M. Guisnet, Deactivation and regeneration of zeolite catalysts, in: M. Guisnet, F.R. Ribeiro (Eds.), Catalytic Science Series, vol. 9, Imperial College Press, London, (2011).

[22] P. Forzatti, L. Lietti, Catal. today, 52 (1999) 165-181.

[23] J.A. Moulijn, A.E. Van Diepen, F. Kapteijn, Appl. Catal. A Gen., 212 (2001) 3-16.

[24] P. Dufresne, Appl. Catal. A Gen., 322 (2007) 67-75.

[25] K. Schlichte, T. Kratzke, S. Kaskel, Microporous Mesoporous Mater., 73 (2004) 81-88.

[26] L. Alaerts, E. Séguin, H. Poelman, F. Thibault- Starzyk, P.A. Jacobs, D.E. De Vos, Chem. Eur J., 12 (2006) 7353-7363.

[27] S.-b. Liu, J.-F. Wu, L.-J. Ma, T.-C. Tsai, I. Wang, J. Catal., 132 (1991) 432-439.

[28] L.-Y. Fang, S.-B. Liu, I. Wang, J. Catal., 185 (1999) 33-42. 
[29] G. Ertl, H. Knozinger, F. Schuth, J. Weitkamp, Handbook of Heterogeneous Catalysis, 8 Volume Set, (2008).

[30] C. Marcilly, Acido-basic catalysis: application to refining and petrochemistry, Technip Ophrys Editions, (2006).

[31] G.E. Giannetto, G.R. Perot, M.R. Guisnet, Ind. Eng. Chem. Prod. Res. Dev, 25 (1986) 481-490.

[32] M. Guisnet, Catal. Today, 218 (2013) 123-134.

[33] X. Bai, A. Samanta, B. Robinson, L. Li, J. Hu, Ind. Eng. Chem. Res., (2018).

[34] C. Tiseanu, B. Gagea, V.I. Parvulescu, V. Lórenz-Fonfría, A. Gessner, M.U. Kumke, Langmuir, 23 (2007) 6781-6787.

[35] A. Aho, N. Kumar, K. Eränen, T. Salmi, M. Hupa, D.Y. Murzin, Fuel, 87 (2008) 24932501.

[36] V. Zholobenko, A. Garforth, J. Dwyer, Thermochimica acta, 294 (1997) 39-44.

[37] M. Aldossary, The Alkylation of 2-Butene with Isobutane over Large-Pore Zeolites, (2018).

[38] T. Matsuda, M. Asanuma, E. Kikuchi, Appl. catal., 38 (1988) 289-299.

[39] X. Zaiku, B. Jiaqing, Y. Yiqing, C. Qingling, Z. Chengfang, J. Catal., 205 (2002) 58-66.

[40] G.S. Nivarthy, Y. He, K. Seshan, J.A. Lercher, J. Catal., 176 (1998) 192-203.

[41] C. Flego, I. Kiricsi, W.O. Parker, M.G. Clerici, Appl. Catal. A Gen., 124 (1995) 107119.

[42] N.S. Gnep, M.L.M. de Armando, M. Guisnet, Reac. Kinet. Catal. Lett., 13 (1980) 183189.

[43] J.M. Serra, E. Guillon, A. Corma, J. Catal., 232 (2005) 342-354. 